Guest Editorial

\title{
Whither Deleuze and Guattari: a critical introduction
}

Journal of International Relations and Development (2010) 13, 323-324. doi:10.1057/jird.2010.5

Years ago at a workshop one of our colleagues, whose name we shall keep anonymous, claimed - to the amusement of the participants - that International Relations (IR) is where theory goes to die. Given the vicissitudes of intellectual fads that sweep through IR, one could, perhaps, be forgiven for condemning what appears to be the superficiality of the theoretical engagements within the field. From another perspective, though, this judgement could be considered unfair, and that the convergence of so many disparate theoretical interventions in IR is actually a testament to its growing vitality. Though many scholars now label themselves constructivists, this is quite a polyglot category that seems to indicate a movement beyond the contrived inter-school debates rather than the rise of a new intellectual hegemony.

As IR scholars, we need to be wary of creeping disciplinising politics that compel us, as in the past, to line up in clearly delineated camps of thought. Given the conjunctural developments of the last few years, from the limits of US power evidenced in Iraq and Afghanistan, to the unsustainability of neoliberal governance shown in the global financial crisis, to the growing significance of the BRIC nations, certain scholars might take this as evidence of the return of realism (or the banal caricature of it, that is). With the work of critical scholarship having availed us a keener understanding of the politics of theory, and its role in normalising world order, we must be vigilant of attempts to recapture IR as a 'state science', a science of governmentality, that works to constrict political agency. In International Relations, ground has been cleared for a new science of social relations, a science that is not bound by a narrow rationalism, but is inherently creative.

It is in this endeavour to expand and preserve the sphere for creative science within IR that we put forth this special issue drawing on the work of Gilles Deleuze and Félix Guattari. The six articles that this issue brings together turn to Deleuze and Guattari not because they offer a new school or encompassing theoretical framework for understanding international politics, but rather because they help to activate our political consciousness in theorising 
the issues that confront us in the contemporary epoch. Just as the work of Deleuze and Guattari represented a resistance to the totalising structures and knowledges that extirpate difference and suffocate the potential of being, we present a series of divergent and creative readings of Deleuze and Guattari that unsettle and dereify the way we view the dynamics of international politics.

In this vein, the aim of this special issue is not to ring-fence a new approach, or to lay out a new canon, but to engage in an agonistic dialogue with our readers, a dialogue that will inoculate scholarship from the return of stultifying reductionism. We are not making claims to a 'licensed' approach, and hope that from these articles the reader comes away with an appreciation of the open-endedness of a Deleuzoguattarian reading of international politics.

We would like to thank the editorial team of the Journal of International Relations and Development for its tremendous support in making this special issue a possibility, as well as for creating a unique forum through this journal for heterodox scholarship within IR. We would also like to thank Giles Simon for organising the original panel on Deleuze and International Politics at the Political Studies Association Conference in Reading. This in turn gave rise to a subsequent panel at the International Studies Association Convention in Chicago, which resulted in the articles contained herein. Thanks also to the audience members who attended these panels for their invaluable feedback.

Earl Gammon and Julian Reid 